\title{
LA FORMACIÓN DE GUARDACOSTAS LIBIOS: HACIA UN MODELO DE SINERGIA DE POLÍTICAS EN LA GESTIÓN INTEGRADA DE FRONTERAS MARÍTIMAS EUROPEAS
}

MIGUEL A. ACOSTA SÁNCHEZ

Universidad de Cádiz

miguelangel.acosta@uca.es

Cómo citar/Citation

Acosta Sánchez, M. A. (2019).

La formación de guardacostas libios: hacia un modelo de sinergia de políticas en la gestión integrada de fronteras marítimas europeas. Revista de Derecho Comunitario Europeo, 64, 859-895. doi: https://doi.org/10.18042/cepc/rdce.64.03

\section{Resumen}

La crisis migratoria que está golpeando el continente europeo procedente particularmente de las costas libias ha provocado la reacción de la UE a través de diversos mecanismos de respuesta y combinando medios de política interior y exterior. Así, se están aplicando acciones en los ámbitos tanto de la Política Común de Seguridad y Defensa como del Espacio de Libertad, Seguridad y Justicia. En estos ámbitos, uno de los elementos más destacados es la formación de guardacostas libios, dentro de estándares internacionales y europeos, a fin de capacitarlos para el control y la gestión

1 Profesor titular de Derecho Internacional Público y Relaciones Internacionales en la Universidad de Cádiz. Trabajo realizado en el marco del Proyecto de I+D «España, seguridad y fronteras exteriores europeas en el área del Estrecho», DER2015-68174-R, investigadores principales A. del Valle Gálvez e I. González García. Proyecto financiado por el Ministerio de Economía y Competitividad y Fondos FEDER de la UE; así como del Centre of Excellence Jean Monnet 'Migration and Human Rights in Europe's External Borders' - With the support of the Erasmus+ Programme of the European Union (587177-EPP-1-2017-1-ES-EPPJMO-CoE). 
de sus propias fronteras exteriores marítimas. No obstante, esta formación se lleva a cabo por parte de varias acciones que difícilmente presentan elementos coherentes de funcionamiento. Por ello, se propone un modelo de sinergia entre políticas, tanto interiores como exteriores, y en el marco del Servicio Europeo de Acción Exterior.

\title{
Palabras clave
}

Gestión integrada de fronteras; fronteras marítimas; guardacostas; Política Común de Seguridad y Defensa; Espacio de Libertad, Seguridad y Justicia.

\section{THE TRAINING OF LIBYAN COASTGUARDS: TOWARDS A MODEL OF SYNERGY OF POLICIES IN THE INTEGRATED MANAGEMENT OF EUROPEAN MARITIME BORDERS}

\begin{abstract}
The migratory crisis that is hitting European continent, particularly from the Libyan coast has provoked the reaction of the EU through various response mechanis$\mathrm{ms}$ and combining internal and external policy. This is applying actions in the areas of the Common Security and Defense Policy as well as the Area of Freedom, Security and Justice. In these areas, one of the most outstanding elements is the formation of Libyan coastguards, within International and European standards, in order to train them for the management and control of their own external maritime borders. However, this training is carried out by several actions that hardly present coherent elements of operation. Therefore, a model of synergy between policies, both internal and external ones, and within the framework of the European External Action Service is proposed.
\end{abstract}

\section{Keywords}

Integrated management of borders; maritime borders; coastguard; Common Security and Defense Policy; Area of Freedom, Security and Justice.

\section{LA FORMATION DES GARDE-CÔTES LIBYENS: VERS UN MODĖLE DE SYNERGIE DES POLITIQUES DE GESTION INTEGRÉE DES FRONTIÈRES MARITIMES EUROPÉENNES}

\section{Résumé}

La crise migratoire qui frappe le continent européen, en particulier depuis la côte libyenne a provoqué la réaction de l'UE par le biais de divers mécanismes de réponse et en combinant politique intérieure et politique étrangère. Cela concerne des actions dans les domaines de la politique commune de sécurité et de défense ainsi 
que de l'Espace de liberté, de sécurité et de justice. Dans ces cadres, l'un des éléments les plus remarquables est la formation des garde-côtes libyens, dans les normes internationales et européennes, a fin de les former à la gestión et le contrôle de leurs propres frontières maritimes extérieures. Cependant, cette formation est réalisée par plusieurs actions qui présentent à peine des éléments de fonctionnement cohérents. Par conséquent, on est proposé un modèle de synergie entre les politiques, à la fois intérieur et extérieur, et dans le cadre du Service européen pour l'action extérieure.

\section{Mots clés}

Gestion intégrée des frontières; frontières maritimes; garde côtière; Politique commune de sécurité et de défense; Espace de liberté, de sécurité et de justice. 


\section{SUMARIO}

I. INTRODUCCIÓN. II. LIBIA Y LAS RELACIONES CON LA UNIÓN EUROPEA EN EL CONTEXTO MIGRATORIO Y DE CONTROL FRONTERIZO. III. LA FORMACIÓN DE GUARDACOSTAS EN EL MARCO DE LA GESTIÓN INTEGRADA DE FRONTERAS EXTERIORES. IV. LA LABOR DE LA UNIÓN EUROPEA EN LA FORMACIÓN DE GUARDACOSTAS LIBIOS: 1. Acciones en el ámbito de la Política Común de Seguridad y Defensa. 2. Acciones en el ámbito del Espacio de Libertad, Seguridad y Justicia. 3. El apoyo a Italia. V. LA NECESARIA SINERGIA DE POLÍTICAS EUROPEAS: UNA PROPUESTA. VI. IDEAS FINALES. BIBLIOGRAFíA.

\section{INTRODUCCION}

La gravísima crisis de refugiados que se está viviendo actualmente en el continente europeo encuentra una de sus facetas más dramáticas en el éxodo de inmigrantes por vía marítima desde las costas de Libia². Las diversas medidas que la UE ha adoptado en estos últimos años no parecen haber dado los frutos esperados. Es más, la crisis está afectando claramente a los valores esenciales del proceso de integración europea por la falta de solidaridad entre los Estados miembros y, en nuestra opinión, por la falta de coherencia en la acción exterior europea (Del Valle Gálvez, 2016b).

En el presente estudio, y teniendo en cuenta esta realidad, pretendemos determinar el grado de sinergia entre las diversas operaciones que la UE ha

2 Según datos de la Organización Internacional para las Migraciones, en 2017 llegaron 171635 inmigrantes vía marítima a Europa y hubo 704625 solicitudes de protección internacional en los Estados miembros. Esta última cifra se ha reducido en 2018 hasta las 634 700. Igualmente, se produjeron 15652 muertes registradas en el mar entre 2015 y 2017, siendo la cifra en 2017 de 3139. En el caso de España, se han registrado, según ACNUR, 64120 llegadas vía marítima en 2018, muy por encima de las registradas en 2017, que ascendían a 28 587. Véase, Del Valle Gálvez (2016a). Igualmente, Asociación Pro Derechos Humanos de Andalucía (2019); Comité Español de Ayuda al Refugiado (2018); Frontex (2018). Igualmente, Comunicación de la Comisión al Parlamento Europeo, al Consejo Europeo y al Consejo, Informe de situación sobre la aplicación de la Agenda Europea de Migración, COM (2019) 126 final (8 de marzo de 2019). 
lanzado en Libia, especialmente las encuadradas en la Política Común de Seguridad y Defensa (en adelante, PCSD), así como en el marco del Espacio de Libertad, Seguridad y Justicia, con objeto de determinar si realmente estamos ante un modelo coherente y particularmente efectivo en la gestión integrada de las fronteras exteriores en el ámbito marítimo. Para ello, nos centraremos en uno de los componentes de la gestión integrada de fronteras, a través de la cooperación con terceros Estados de tránsito u origen de la inmigración, y traducido en la labor de formación de los guardacostas. Esta formación está siendo gestionada por diversas iniciativas europeas, las cuales están sufriendo severas críticas en los últimos tiempos por la supuesta vulneración de los derechos humanos por parte de las autoridades libias ${ }^{3}$. El análisis nos debe permitir determinar si estamos ante un modelo válido en la combinación de medidas de política interior y exterior, y frente a una situación de extrema complejidad como son las migraciones vía marítima en el Mediterráneo; o si es necesario establecer otros mecanismos más imaginativos de coordinación de todas las acciones lanzadas por la UE en materia de formación de guardacostas.

\section{LIBIA Y LAS RELACIONES CON LA UNIÓN EUROPEA EN EL CONTEXTO MIGRATORIO Y DE CONTROL FRONTERIZO}

Como es bien sabido, el tremendo fenómeno mundial que representaron las denominadas primaveras árabes tuvo igualmente impacto en Libia. En efecto, en este Estado se decidió oponer resistencia militar y utilizar medios y métodos de guerra contra las manifestaciones populares, sin ninguna posibilidad de diálogo (Blanc Altemir, 2012; Mangas Martín, 2011)4. Se pasó además de meros disturbios a un auténtico conflicto armado con violación sistemática de los Convenios de Ginebra y sus protocolos adicionales. Tras la caída de Gadafi (Hermoso, 2016), se organizaron elecciones generales en 2012, siendo elegido el Congreso General Nacional (en adelante, CGN) a fin de completar la transición mediante la elaboración de una Constitución. No obstante, desde el primer momento y debido al sistema mixto de elección, esto es, una parte elegida a partir de listas de partidos políticos y otra a través de candidaturas individuales, el funcionamiento del CGN fue excesivamente complejo. $\mathrm{Y}$ es que hay que tener en cuenta la naturaleza propia de Libia, la

3 Véase, como ejemplo, Tribunal Europeo de Derechos Humanos, S.S. et autres contre l'Italie, Demanda n. ${ }^{\circ}$ 21660/18, de 3 de mayo de 2018.

4 Véase Improving the Effectiveness of Capabilities (IE) in EU Conflict Prevention (IECEU), The Libya review, de 13 de febrero de 2017 y la bibliografía allí citada. 
cual se encuentra formada por numerosas regiones y tribus sin que existan elementos cohesionadores entre ellos. Únicamente un régimen dictatorial como el de Muamar el Gadafi fue capaz de mantener unido a todo el territorio; con su ausencia, el país se ha descompuesto totalmente, provocando la violencia entre grupos armados repartidos por todo el país. Con todo, nos encontramos actualmente con un Gobierno internacionalmente reconocido - actual Gobierno del Consenso Nacional-y derivado del $\mathrm{CGN}^{5}$, con sede en Trípoli, y un segundo Gobierno, con sede en Tobruk. A ellos se le ha añadido un elemento internacional, al recibir los primeros apoyos desde Qatar, y los segundos de Emiratos Árabes y Egipto. En paralelo, el vacío de poder ha permitido la entrada de grupos terroristas vinculados al Estado Islámico, particularmente en la frontera sur (Echeverría Jesús, 2018: 114-115).

En diciembre de 2015 se lanzó un Plan de Acción a fin de lograr un consenso entre las partes y convocar nuevas elecciones (Cervell Hortal, 2013) ${ }^{6}$, si bien tuvo escaso éxito debido a la complejidad de la realidad libia, lo que conllevó un incremento de las hostilidades entre los grupos armados. En septiembre de 2017 se presentó un nuevo proyecto, sin que nuevamente obtuviera el respaldo de todas las partes. Aun a pesar de que dicho plan represente para algunos sectores un fracaso, la comunidad internacional continua celebrando cumbres internacionales de apoyo al mismo, como la celebrada en Palermo en noviembre de $2018^{7}$. No obstante, la situación de seguridad sigue siendo muy volátil. Así, mientras en la capital se ha aprobado un nuevo plan de seguridad general, en la región occidental del país la situación sigue siendo inestable, con enfrentamientos entre grupos armados; y en el sur, en el basto margen fronterizo, se ha producido un deterioro de las condiciones socioeconómicas. Las diversas milicias esparcidas por todo el país siguen cometiendo violaciones de los derechos humanos, afectando de forma directa a los inmigrantes y necesitados de protección internacional, y sin que exista un control centralizado (Amnesty International, 2017; Hernández Ospina y García Perilla, 2018; Mancini, 2017) ${ }^{8}$. A ello se añade, además, la toma de Trípoli

5 Resoluciones del Consejo de Seguridad 2259 (2015) de 23 de diciembre, y 2278 (2016) de 31 de marzo. Igualmente, Rodríguez (2016).

6 Véase Resolución del Consejo de Seguridad 2441 (2018), de 5 de noviembre.

7 En dicha cumbre cabe destacar que los Estados participantes insistieron en apoyar el Plan de Paz para Libia, además de comprometerse a prestar asistencia para la formación de las fuerzas de seguridad libias, entre otras medidas. Véase, Wehrey y Harchaoui (2018).

8 «De un total de 57468 refugiados y solicitantes de asilo registrados en el ACNUR en Libia, 1623 personas fueron registradas durante el periodo sobre el que se informa. Más de 5300 migrantes y refugiados fueron detenidos en dependencias policiales». A 
por las fuerzas del general Haftar y la huida de la capital de las autoridades internacionalmente reconocidas ${ }^{9}$. En cualquier caso, sería necesario que los Estados dejaran de lado sus intereses económicos y comerciales sobre las materias primas libias y se centraran en la protección de los derechos humanos si realmente desean lograr una región libia en paz y estabilidad (International Crisis Group, 2016).

Centrándonos en materia de inmigración y gestión fronteriza, la estructura administrativa libia es bastante compleja, repartiéndose entre varios ministerios, pero estando afectadas, en todo caso, por la actuación de las milicias que imposibilitan una coordinación intergubernamental eficiente en todo el territorio (Lacher, 2013; El Zaidy, 2019) ${ }^{10}$. Así, encontramos competencias sobre las fronteras terrestres, marítimas y aéreas en los ministerios de Interior y Finanzas, los servicios de inteligencia y el Departamento de Investigación General, y el Ministerio de Transporte. Aun cuando deberíamos entender que existe una coordinación entre todas ellas, dada la situación volátil de la seguridad, las acciones operativas de la UE sobre el terreno han encontrado y encuentran enormes dificultades en localizar un interlocutor válido; prueba de ello es que en la zona sur la gestión fronteriza se lleva a cabo por las comunidades locales, sin apenas control de las autoridades gubernamentales.

En el Ministerio del Interior existen hasta tres direcciones generales sobre gestión fronteriza: Seguridad Fronteriza, Seguridad Costera ${ }^{11}$ y Lucha contra la Migración Ilegal. Dentro del Ministerio de Defensa, en materia fronteriza poseen competencias la guardia costera y de seguridad portuaria, así como

principios de julio de 2018, más de 53000 refugiados y peticionarios de asilo estaban registrados en ACNUR Libia. Véase Informe del Secretario General sobre la Misión de Apoyo de las Naciones Unidas en Libia, UN Doc S/2019/19 (7 de enero de 2019), p. 12. Igualmente, Improving the Effectiveness of Capabilities (IE) in the EU Conflict Prevention (IECEU), The Libya review, cit., nota 4, pp. 41-43.

9 Véase Informe del Secretario General sobre la Misión de Apoyo de las Naciones Unidas en Libia, UN Doc S/2019/682 (26 de agosto de 2019). Igualmente, Kekilli (2019).

10 Véase EUBAM Libya Initial Mapping Report Executive Summary, Working document, Doc. EEAS (2017) 0109 (24 de enero de 2017), pp. 35-46.

11 La Dirección General para la Seguridad Costera es la entidad ejecutiva establecida dentro del Ministerio del Interior y encabezada por un director general, y con competencias hasta las doce millas naúticas. Más allá, es responsabilidad de los guardacostas libios pertenecientes al Ministerio de Defensa. Son igualmente responsables de la banda terrestre hasta treinta kilómetros tierra adentro. A nivel internacional, ha participado junto con Frontex, y gracias a la labor de la operación civil de la UE EUBAM Libia, en la creación de la Coast Guard Cooperation Network. Véase supra nota 10. 
los guardias de fronteras ${ }^{12}$. En todo caso hay una cooperación con las operaciones EUBAM-Libia y Sophia, en el contexto de la PCSD, la Guardia Civil española a través de la Red Seahorse, así como Frontex y el Servicio Europeo de Acción Exterior.

Vemos entonces que se produce una primera distinción territorial de control fronterizo marítimo, de tal forma que el Ministerio del Interior, a través de la Dirección General de Seguridad Costera, tendría competencias hasta las doce millas marítimas, mientras que el Ministerio de Defensa, por medio de guardacostas que serían parte de la Armada libia, actuarían más allá del Mar Territorial, si bien no en exclusiva. Ello conllevaría una primera duplicación de funciones ratione loci especialmente en la zona SAR (Search and Rescue) bajo competencia libia. Con todo, el sistema de gestión fronteriza libio carece de una visión central y organización estratégica, debido en buena parte a la existencia de las milicias repartidas por todo el territorio, a lo que hay que añadir el conflicto armado interno. Además, existe una clara falta de equipamiento e infraestructura, así como de mando central y control, lo que conlleva riesgos para la ejecución de sus funciones, especialmente en la zona sur.

Respecto al papel de la UE en el conflicto, debemos indicar que ha sido bastante dispar ${ }^{13}$. En el ámbito diplomático y económico, la delegación en Libia se abrió en 2011 en Trípoli, pero debido a la escalada de violencia especialmente en 2014, fue trasladada a Túnez. Igualmente, a través del Cuarteto para Libia, la UE mantiene relaciones con la Liga de Estados Árabes, la Unión Africana y Naciones Unidas ${ }^{14}$. Por otra parte, en los primeros momentos la

12 En el Ministerio de Defensa, la Guardia Costera y de Seguridad Portuaria es parte de la Armada libia. Ejerce la soberanía y la aplicación de la normativa en el Estado libio, dentro de sus aguas, y de acuerdo con el Convenio de Naciones Unidas sobre el Derecho del Mar, aun cuando Libia no haya ratificado a fecha de hoy dicho Convenio. Entre sus tareas se encuentra la vigilancia de las aguas nacionales, el control y lucha de los tráficos ilegales por mar, las zonas SAR y las relaciones bilaterales e internacionales. El 14 de diciembre de 2017, las autoridades libias remitieron una comunicación a la OMI para informarle de que el Gobierno libio había declarado la región SAR, la cual no parece que se superponga a otras y sus países vecinos no la han protestado. La región SAR fue formalmente recogida por la OMI en el Global Integrated Shipping Information System de 27 de junio de 2018.

13 Véase, sobre el apoyo de la UE a Libia, Conclusiones del Consejo sobre Libia, Doc. 11155/17 (17 de julio de 2017). Igualmente, El Zaidy (2019).

14 En el contexto de la Cumbre UE-UA de noviembre de 2017, estas dos organizaciones junto con Naciones Unidas han establecido una Task Force para acelerar los programas de la Organización Internacional de Migraciones (OIM) a fin de asistir en el retorno voluntario y el mecanismo de tránsito de emergencia de ACNUR. Véase la 
UE realizó un importante esfuerzo diplomático, incluyendo una ayuda de 80 millones de euros en ayuda humanitaria. Actualmente, la UE desarrolla proyectos y actividades en Libia por valor de 374 millones de euros, especialmente para favorecer a medio y largo plazo el proceso político, la reconciliación y elecciones constitucionales, la protección de los derechos humanos y el empoderamiento de la mujer, la reforma económica, seguridad y justicia, gestión fronteriza y migraciones, entre otros ${ }^{15}$. La ayuda se lleva a cabo a través del Fondo Europeo de Estabilidad ${ }^{16}$, el Instrumento Europeo de Vecindad ${ }^{17}$ así como el Fondo Fiduciario de la UE para África ${ }^{18}$.

En el ámbito político y operacional, la UE, apoyándose en el tenor de la Resolución del Consejo de Seguridad 1973 (2011) de 17 de marzo, aprobó en 2011 una operación militar (EUFOR Libia) a fin de garantizar la asistencia humanitaria. Sin embargo, la operación jamás llegó a activarse debido a la inseguridad existente, lo cual impidió que la Oficina de Coordinación de Asuntos Humanitarios de las Naciones Unidas (OCAH) solicitara formalmente su activación, tal y como recogía el art. 1 de la decisión de creación ${ }^{19}$. Posteriormente, y tras el inicio de la crisis de refugiados, se aprobó una misión

Joint Statement on the Migrant Situation in Libya, accesible en https://bit.ly/2BTcYci (consultado el 1 de octubre de 2019).

15 Así, en febrero de 2018, la Comisión adoptó tres programas por valor de más de 150 millones de euros a fin de abordar la situación de los migrantes en Libia y apoyar su retorno y reintegración en África. Véase, La Ley Unión Europea, 2018, n. ${ }^{\circ} 57$. Igualmente, Calvo Mariscal (2018).

16 El Fondo de Estabilización de la UE ha previsto doce millones de euros para el periodo 2016-2019. Se destinarán especialmente para la mejora y rehabilitación, entre otros, de hospitales, escuelas y universidades.

17 A través del Instrumento de Vecindad, la UE contribuye a la capacidad de construcción de las instituciones nacionales libias en áreas de administración pública, desarrollo socioeconómico y sector de la salud. Véase Comunicación de la Comisión al Parlamento Europeo, al Consejo Europeo, al Consejo y al Banco Europeo de Inversiones, sobre la creación de un nuevo Marco de Asociación con terceros países en el contexto de la Agenda Europea de Migración, COM (2016) 385 final (7 de junio de 2016), pp. 17-18.

18 Véase Tribunal de Cuentas, Informe Especial no 32/2018 - Fondo Fiduciario de Emergencia de la Unión Europea para África: flexible, pero insificientemente enfocado, DO C 444, de 10 de diciembre de 2018.

19 Véase Decisión 2011/210/PESC del Consejo, de 1 de abril de 2011, sobre una operación militar de la Unión Europea en apoyo de las operaciones de asistencia humanitaria como respuesta a la situación de crisis existente en Libia (EUFOR Libia), DO L 89, de 5 de abril de 2011. Una crítica sobre el papel de la UE, en Esteve Moltó (2014); Ferrer Lloret (2012). 
civil (EUBAM Libia) con el objetivo de ayudar a potenciar la gestión integrada de las fronteras por mar, tierra y aire ${ }^{20}$. Cabe destacar que la compleja situación existente en Libia, a la cual podríamos considerar como un Estado fallido, conllevó que esta operación civil tuviera que ubicarse temporalmente en Túnez y hasta diciembre de 2017 no ha podido volver a Trípoli ${ }^{21}$.

Siguiendo en el ámbito PCSD, se ha lanzado igualmente la operación militar naval EUNAVFOR MED Sophia ${ }^{22}$, centrada en detectar, capturar y eliminar los buques y medios que utilizan o que se sospeche que utilizan las bandas criminales para el tráfico de personas. Igualmente, proporciona formación a la guardia costera y a la Armada libias, y contribuye a garantizar el embargo de armas impuesto por las resoluciones del Consejo de Seguridad.

En el contexto del Espacio de Libertad, Seguridad y Justicia, y en materia de control y vigilancia de fronteras, Frontex lanzó la operación naval Tritón, como complemento de la operación naval italiana Mare Nostrum (Pérez Quiles, 2018; Vacas Fernández, 2016). Esta operación ha cubierto las aguas territoriales de Italia y las zonas SAR de Italia y Malta, representando así un mecanismo de control de la inmigración irregular procedente de Libia. Desde febrero de 2018, ha sido sustituida por la operación Themis, la cual cubre las aguas de Argelia, Túnez, Libia, Egipto, Turquía y Albania ${ }^{23}$.

Recientemente, se ha creado una Célula de Planificación y Enlace de la UE (EU Liaison and Planning Cell - EULPC) cuya función es apoyar a la misión de apoyo de Naciones Unidas en Libia (UNSMIL) en la operatividad de los aspectos civiles y policiales en el ámbito de la seguridad libia. Esta célula, si bien con gran retraso en su implantación, debe aportar un vital apoyo de planificación militar y capacidad de inteligencia a la operación onusiana. Por otro lado, su rol como enlace local de todas las acciones operativas tanto en el ámbito de la PCSD como del Espacio de Libertad, Seguridad y Justicia representa, a todas luces, un primer paso en la buena dirección hacia una si-

20 Decisión 2013/233/PESC del Consejo, de 22 de mayo de 2013, sobre la Misión de de la Unión Europea de asistencia y gestión integrada de las fronteras en Libia (EUBAM Libia), DO L 138, de 24 de mayo de 2013.

21 Véase Resolución del Parlamento Europeo, de 15 de enero de 2015, sobre la situación en Libia, DO C 300, de 18 de agosto de 2016. Igualmente, Hermoso (2016: 176177). También, EUBAM Factsheet, Updated in March 2019, accesible en: https://bit. ly/2q59Sz2 (visitado el 1 de octubre de 2019).

22 Decisión 2015/778/PESC del Consejo, de 18 de mayo de 2015, relativa a una operación militar de la Unión Europea en el Mediterráneo central meridional, DO L 122, de 19 de mayo de 2015.

23 Fontex New Release, "Frontex launching new operation in Central Med", de 1 de febrero de 2018. 
nergia competencial sobre el terreno y ante una crisis internacional como es la libia. No obstante, su implantación, así como su posible exportación a otras situaciones, debería clarificarse estructuralmente. Ejemplo de estas lagunas es su composición únicamente por expertos militares, sin contar, inicialmente con personal especializado en el ámbito policial o funcionarial ${ }^{24}$.

No obstante, sigue existiendo gran inseguridad, especialmente en la zona sur, donde el control fronterizo es inexistente ${ }^{25}$. A fecha de hoy, no existe una estrategia única e independiente hacia Libia. En nuestra opinión, no parece que se hayan tenido en cuenta las características tan particulares del país y la naturaleza de su conflicto, por lo que erróneamente se acude a instrumentos tipo, utilizados en otras regiones geográficas, pero que en este caso no están dando los mismos resultados (Ekiz, 2018; Díez Alcalde, 2013; International Crisis Group, 2017).

\section{LA FORMACIÓN DE GUARDACOSTAS EN EL MARCO DE LA GESTIÓN INTEGRADA DE FRONTERAS EXTERIORES}

La denominada "gestión integrada de fronteras exteriores» ha sido reconocida en el actual Tratado de Lisboa y como continuación del fracasado Tratado por el que se establece una Constitución Europea (art. III-265). El art. 77.1 c) TFUE, en lo referente al control y vigilancia de las fronteras exteriores, indica que: «1. La Unión desarrollará una política que tendrá por objetivo: [...] c) Instaurar progresivamente un sistema integrado de gestión de las fronteras exteriores».

No obstante, no parece que este objetivo tenga una clara ejecución, como pudieran tener las políticas de asilo o de inmigración, de tal forma que el art.

24 Así, la célula está formada por ocho expertos militares bajo la dirección de un experto en seguridad en la dirección de la Delegación de la UE en Libia, bajo la dirección funcional del Servicio Europeo de Acción Exterior (en adelante, SEAE). Véase Strategic Review on EUNAVFOR MED Operation Sophia, EUBM Libya \& EU Liaison and Planning Cell, de 27 de julio de 2018 [EEAS (2018) 835], pp. 67-72.

25 En este contexto, la UE está apostando por su apoyo político y económico al G-5 Sahel. El G-5 Sahel, validado por Resolución del Consejo de Seguridad 2359 (2017) de 21 de junio, es la primera organización africana que aporta un enfoque integral para solucionar problemas de seguridad combinándola con el desarrollo. Lo forman Burkina Faso, Mali, Mauritania, Níger y Chad, con el apoyo expreso de la UE. Véase Mora Tebas (2017). Igualmente, Conclusiones del Consejo sobre Libia, Doc. 11155/17 (17 de julio de 2017); Informe del Secretario General sobre la Fuerza Conjunto del Grupo de los Cinco del Sahel, UN Doc S/2019/371 (6 de mayo de 2019). 
77.2 d) TUE se limita a indicar que «el Parlamento y el Consejo adoptarán, de acuerdo con el procedimiento legislativo ordinario, cualquier medida necesaria para el establecimiento progresivo de un sistema integrado de gestión de las fronteras exteriores ${ }^{26}$.

En el contexto del Espacio de Libertad, Seguridad y Justicia, esta gestión integrada tendrá como objetivo garantizar la libertad y la seguridad de los ciudadanos en un espacio común, lo cual incluiría el control de las fronteras exteriores, como paradigma de la inclusión del acervo Schengen en los Tratados. De esta forma, este control perseguiría frenar la criminalidad organizada, el terrorismo y las redes de inmigración irregular, a través fundamentalmente de la cooperación de los cuerpos y fuerzas de seguridad nacionales con competencia fronteriza, y con pleno respeto de los derechos humanos ${ }^{27}$.

En nuestra opinión, no parece que haya una definición clara de gestión integrada de fronteras exteriores, encontrándonos, en todo caso, descripciones materiales y funcionales de su contenido ${ }^{28}$. Así, en 2002 la Comisión ${ }^{29}$ indicaba que la «gestión de fronteras exteriores» conllevaba el conjunto de actividades realizadas por los poderes públicos de los Estados miembros, incluyéndose los controles y la vigilancia de las fronteras exteriores; recogida,

26 La cursiva es nuestra. Véase Del Valle Gálvez (2019: 102-103).

27 La política de gestión y control de fronteras es una competencia compartida entre la UE y los Estados miembros. Véase el considerando (6) y art. 5 del Reglamento 2016/1624/UE del Parlamento Europeo y del Consejo de 14 de septiembre de 2016, sobre la Guardia Europea de Fronteras y Costas, por el que se modifica el Reglamento 2016/399/UE del Parlamento Europeo y del Consejo y por el que se derogan el Reglamento 2007/863/CE del Parlamento Europeo y del Consejo, el Reglamento 2004/2007/CE del Consejo y la Decisión 2005/267/CE del Consejo, DO L 251, de 16 de septiembre de 2016 (Reglamento Frontex).

Para Rijpma, la «gestión de fronteras exteriores» se entiende como «the processes and procedures associated with border checks, which take place at authorised crossing points, including airports, and border surveillance, which is carried out on the socalled green (land) borders between authorised crossing points and along the blue (sea) borders». A esta definición se le incluiría las fronteras marítimas. Véase Rijpma (2009: 121). Igualmente, De Bruycker (2016: 563); Santos Vara (2018: 149-152). No parece, en cualquier caso, que se tenga en cuenta la acción de «integrar», la cual implicaría, según la $R A E$, completar un todo con las partes que faltan (primera acepción); o aunar, fusionar dos o más conceptos, corrientes, etc., divergentes entre sí en una sola que los sintetice (quinta acepción).

29 Comunicación de la Comisión al Consejo y al Parlamento Europeo - Hacia una gestión integrada de las fronteras exteriores de los Estados miembros de la UE, COM (2002) 233 (7 de mayo de 2002), p. 23. 
análisis e intercambio de información; y análisis de la evolución de los peligros. Ya en 2008 se comienza a reforzar la idea de una cooperación más allá de las fronteras exteriores, haciendo referencia a la cooperación con terceros Estados $^{30}$; y afianzándose con la crisis migratoria de 2015 y la adopción de la Agenda Europea de Migración ${ }^{31}$.

Con todo, podríamos definir a la "gestión integrada de fronteras exteriores» como aquel instrumento que busca integrar, de acuerdo con parámetros comunes y coordinados, el conjunto de actividades en materia de control y vigilancia de los poderes públicos de los Estados miembros y a fin de garantizar la seguridad fronteriza exterior en pleno respeto de la legislación comunitaria e internacional. Y es el Reglamento 2016/1624/UE por el que se crea la Agencia Europea de Fronteras y Costas (Reglamento Frontex), en su art. 4, donde encontramos los elementos que componen esta gestión integrada. En el punto f) de dicho artículo, se contiene la referencia a la cooperación con terceros países, especialmente en los países vecinos y países de origen y/o tránsito para la inmigración irregular ${ }^{32}$.

En el concreto ámbito marítimo de los guardacostas, uno de los objetivos en la cooperación con terceros Estados sería su formación, en el marco de estándares europeos e internacionales, a fin de desarrollar su actuación en el control y vigilancia fronteriza que permitiera evitar el cruce no autorizado de las fronteras

30 «El concepto de gestión integrada de las fronteras implica una combinación de mecanismos de control y herramientas que varían en función de los flujos de personas que entran en la Unión. Requiere la adopción de medidas en los consulados de los Estados miembros situados en los terceros países, medidas de cooperación con los países terceros vecinos, medidas en las fronteras propiamente dichas y medidas dentro del espacio Schengen». Véase Comunicación de la Comisión al Parlamento Europeo, al Consejo, al Comité Económico y Social Europeo y al Comité de las Regiones - Preparación de los próximos pasos en la gestión de fronteras de la Unión Europea, COM (2008) 69 final (13 de febrero de 2008), p. 3.

31 Comunicación de la Comisión Europea al Parlamento Europeo, al Consejo, al Comité Económico y Social Europeo y al Comité de las Regiones, Una Agenda Europea de Migración, COM (2015) 240 final (13 de mayo de 2015). Un análisis de estas medidas en Del Valle Galvez (2016b: 5-7).

32 El contenido de este art. 4 incluiría: a) control fronterizo; b) operaciones de búsqueda y salvamento en el mar; c) análisis de riesgos para la seguridad interior y las fronteras exteriores de los flujos migratorios; d) cooperación entre los Estados Miembros a través de Frontex; e) cooperación con otras agencias afectadas; f) cooperación con terceros países; g) medidas técnicas y operativas en el espacio Schengen; h) retorno de nacionales de terceros países; i) empleo de tecnología punta; j) un mecanismo de control de calidad, y k) mecanismos de solidaridad. Véase supra nota 27. 
marítimas; la detención, el abordaje, registro, interceptación e incluso el apresamiento del buque; y medidas de búsqueda y salvamento en el mar. En todos los casos se deberán respetar las normas de derecho internacional del mar aplicables en el contexto del auxilio marítimo, en particular el principio de no devolución ${ }^{33}$. No obstante, encontramos una problemática de base en cuanto a las fronteras marítimas. Así, como indica Del Valle (2019: 99-102), es inviable el control fronterizo en este espacio, dada su naturaleza y la imposibilidad para un único Estado de controlar el perímetro marítimo fronterizo, donde encontramos zonas SAR, amplias zonas de Alta Mar — particularmente en el Mediterráneo-, la falta de apoyo de algunos Estados miembros y especialmente las graves crisis internas en los territorios de la orilla sur del Mediterráneo. No obstante, la UE ha procedido a adoptar una ingente cantidad de normativa al respecto que, si bien no ha frenado la llegada masiva de inmigración vía marítima, sí ha creado un corpus iuris de relieve. De este modo, podemos agrupar las medidas en dos grandes paquetes: en primer lugar, el fortalecimiento de Frontex, que ha pasado a denominarse Agencia Europea de la Guardia de Fronteras y Costas (Santos Vara, 2018) ${ }^{34}$; en segundo lugar, la profundización de la cooperación con otros actores en estos ámbitos ${ }^{35}$.

33 Así viene recogido como contenido del control y vigilancia fronteriza en el contexto de la UE. Véase el considerando (1) del Reglamento 2014/656/UE del Parlamento Europeo y del Consejo, de 15 de mayo de 2014, por el que se establecen normas para la vigilancia de las fronteras marítimas exteriores en el marco de la cooperación operativa coordinada por la Agencia Europea para la Gestión de la Cooperación Operativa en las Fronteras Exteriores de los Estados miembros de la Unión Europea, DO L 189, de 27 de junio de 2014; y el art. 13.1 del Reglamento 2016/399/UE del Parlamento Europeo y del Consejo, de 9 de marzo de 2016, por el que se establece un Código comunitario de normas para el cruce de personas por las fronteras (Código de fronteras Schengen), DO L 77, de 23 de abril de 2016.

34 Frontex cuenta con una nueva regulación desde diciembre de 2019 a través del Reglamento 2019/1896/UE, DO L 295, de 14 de noviembre. Véase, igualmente, Reglamento 2014/515/UE del Parlamento Europeo y del Consejo, de 16 de abril de 2014, por el que se establece, como parte del Fondo de Seguridad Interior, el instrumento de apoyo financiero a las fronteras exteriores y los visados y por el que se deroga la Decisión núm. 574/2007/CE, DO L 150, de 20 de mayo de 2014.

35 Entre estos actores se encontrarían el Alto Comisionado de las Naciones Unidas para los Refugiados, la Organización Internacional para las Migraciones, Europol, el Centro de Satélites de la Unión Europea, la Agencia Europea de Defensa, la Agencia Europea de Seguridad Marítima, la Agencia Espacial Europea y el Centro Europeo para la Prevención y el Control de las Enfermedades. Véanse las Conclusiones del Consejo de Justicia e Interior «Sobre 29 medidas destinadas al refuerzo de la protección de las fronteras exteriores y a la lucha contra la inmigración ilegal», Doc. 6855/2/10 REV 2 (25-26 de febrero de 2010). Igualmente, Cumbre de La Valeta sobre inmigración, 
Concretamente, en el ámbito de la cooperación con terceros Estados, el Consejo Europeo, en sus conclusiones de junio de 2018, destacaba el apoyo a Italia y otros Estados miembros en su labor en la lucha contra la inmigración irregular. Igualmente, se mostraba dispuesto a apoyar la formación de la guardia costera libia, buscando mejorar las condiciones de acogida humanas, retornos humanitarios voluntarios, la cooperación con otros países de origen y tránsito, así como el reasentamiento voluntario. Y siempre en pleno respeto de la legalidad internacional ${ }^{36}$.

En paralelo, en el ámbito jurídico internacional en esta materia, el Convenio de Naciones Unidas contra la Delincuencia Organizada Transnacional, de noviembre de 2000 y su «Protocolo contra el tráfico ilícito de inmigrantes por tierra, mar y aire» (Protocolo de Palermo) promueven entre otras medidas la cooperación entre los Estados. A partir de ello, algunos Estados como España o Italia han procedido a establecer acuerdos bilaterales y permitir ejercer un control más allá de sus fronteras — extraterritorial— de la inmigración, práctica que la UE ha seguido igualmente. Ello conlleva una interpretación laxa de las fronteras europeas, o al menos de los puntos donde ejercer el control. De esta forma, nos encontramos agentes de fronteras de Estados miembros realizando labores de control más allá de las fronteras europeas, y con la finalidad de controlar y frenar la llegada de la inmigración irregular al borde exterior europeo. Es lo que se conoce como la externalización del control de fronteras ${ }^{37}$.

$Y$ en este contexto, a fin de dar cobertura legal a equipos policiales que vayan a realizar actuaciones ejecutivas en un tercer Estado u operaciones en las fronteras exteriores con la participación de estos terceros Estados o incluso en las zonas SAR de estos últimos, el art. 54 del Reglamento Frontex prevé la celebración de un acuerdo con dicho tercer Estado y en base a un plan ope-

Comunicado de Prensa, 809/15 (12 de noviembre de 2015); Comunicación de la Comisión al Parlamento Europeo, al Consejo Europeo, al Consejo y al Banco Europeo de Inversiones, sobre la creación de un nuevo Marco de Asociación con terceros países en el contexto de la Agenda Europea de Migración, COM (2016) 385 final (7 de junio de 2016). Véase, igualmente, Informe de la Comisión al Parlamento Europeo, al Consejo Europeo y al Consejo, Cuarto Informe de situación sobre el Marco de Asociación con terceros países en el contexto de la Agenda Europea de Migración, COM (2017) 350 final (16 de junio de 2017). Sobre el apoyo a esta cooperación con terceros Estados, véanse las Conclusiones del Consejo Europeo, Doc. EUCO 14/17 (19 de octubre de 2017).

36 Conclusiones del Consejo Europeo, Doc. EUCO 9/18 (28 de junio de 2018). Igualmente, Sánchez Legido (2019: 6).

37 Del Valle prefiere conceptuarlo como «desterritorialización». Véase Del Valle Gálvez (2019: 104-110) y la bibliografía allí citada. 
rativo. El acuerdo a celebrar deberá establecer el alcance de la operación, la responsabilidad civil y penal y las funciones y competencias de los miembros del equipo - las cuales deberán desarrollarse bajo las instrucciones y en presencia de agentes de la guardia de fronteras del tercer Estado-, los privilegios e inmunidades, así como el pleno respeto de los derechos fundamentales. Es interesante destacar que la estructura sigue la práctica de la UE con ocasión de sus operaciones civiles y militares en el ámbito PCSD, por lo que nos encontramos ante un sistema que permite facilitar la organización y logística en el seno del Consejo ${ }^{38}$. Otra cuestión distinta es lo relativo al grado de responsabilidad de la UE en la ejecución de este tipo de operaciones cuando se llevan a cabo en las aguas bajo soberanía o jurisdicción de terceros Estados y pudieran afectar a los derechos fundamentales, como es el derecho de una persona a salir de su propio país (Acosta Sánchez, 2018b: 54-56; Del Valle Gálvez, 2019: 106-110; Sánchez Legido, 2019: 20-24).

\section{LA LABOR DE LA UNIÓN EUROPEA EN LA FORMACIÓN DE GUARDACOSTAS LIBIOS}

En el contexto de la gestión integrada de fronteras exteriores y en sus relaciones con Libia, la voluntad de la UE ha sido fortalecer a la Administración General de Seguridad Costera (Ministerio del Interior) y a los guardacostas (Ministerio de Defensa) a través de su capacitación en la vigilancia en las áreas costeras, en términos de patrulla, transporte y rescate de acuerdo con el derecho internacional; además de crear un Centro de Coordinación en Trípoli, si bien este objetivo no se ha logrado hasta la fecha. La finalidad última es lograr elaborar una estrategia sobre seguridad y gestión fronteriza libia ${ }^{39}$.

Ya en febrero de 2010, cuando el Consejo aprobó las veintinueve medidas destinadas al refuerzo de la protección de las fronteras exteriores y a la

38 Comunicación de la Comisión al Parlamento Europeo y al Consejo, Modelo de acuerdo sobre el estatuto conforme a lo dispuesto en el artículo 54, apartado 5, del Reglamento (UE) 2016/1624 del Parlamento Europeo y del Consejo, de 14 de septiembre de 2016, sobre la Guardia Europea de Fronteras y Costas, COM (2016) 747 final (22 de noviembre de 2016). Ya hemos tenido algunos ejemplos en este ámbito, celebrándose acuerdos con la República de Albania (Decisión 2018/1031/UE del Consejo de 13 de julio de 2018, DO L 185, de 23 de julio de 2018), Macedonia del Norte (Decisión 2018/1031/UE del Consejo de 13 de julio de 2018, DO L 257, de 15 de octubre de 2018) y Montenegro (Decisión 2019/453/UE del Consejo de 13 de julio de 2018, DO L 79, de 21 de marzo de 2019).

39 Strategic Review on EUNAVFOR MED Operation Sophia..., cit., nota 24, p. 16. 
lucha contra la inmigración ilegal ${ }^{40}$, se hacía referencia expresa a la necesaria cooperación con Libia en el ámbito marítimo y de gestión de fronteras. Esta cooperación implicaría igualmente la posibilidad de patrullas conjuntas e incluso la propia formación. Y ello tendrá su activación tanto en el ámbito policial como militar, complementándose con las actividades de formación para la guardia costera y la marina libia ${ }^{41}$. Igualmente, en la Cumbre de La Valeta del Consejo Europeo de 3 de febrero de 2017 se identificaban como elementos prioritarios la formación, equipos y apoyo a la guardia costera nacional libia —a través de la labor del Gobierno italiano- , así como otros organismos pertinentes, contribuyendo de tal forma a reducir la presión sobre las fronteras de Libia y trabajando con sus vecinos. Entre estos últimos se citan a Túnez, Argelia y Egipto y la urgencia de potenciar mecanismos de cooperación transfronteriza con todos ellos ${ }^{42}$.

Todas estas iniciativas se han llevado a cabo por medio de una serie de medidas de muy diversa índole y que aparentan sufrir de una falta de coordinación entre ellas. Vemos, de este modo, medidas en el ámbito de la PCSD pero igualmente del Espacio de Libertad, Seguridad y Justicia, e incluso fondos europeos destinados a la capacitación de los guardacostas por parte de las autoridades italianas.

\section{ACCIONES EN EL ÁMBITO DE LA POLÍTICA COMÚN DE SEGURIDAD Y DEFENSA}

En el marco de la PCSD, la acción de formación tanto policial como militar en terceros Estados aparece recogida dentro de las operaciones de paz de-

40 Conclusiones del Consejo de Justicia e Interior «Sobre 29 medidas destinadas al refuerzo de la protección de las fronteras exteriores y a la lucha contra la inmigración ilegal», cit., nota 35 .

41 Véase Comunicación de la Comisión al Parlamento Europeo, al Consejo Europeo, al Consejo y al Banco Europeo de Inversiones, sobre la creación de un nuevo Marco de Asociación con terceros países en el contexto de la Agenda Europea de Migración, COM (2016) 385 final (7 de junio de 2016), p. 17.

42 Cumbre de La Valeta, Declaración de Malta de los miembros del Consejo Europeo sobre los aspectos exteriores de la migración: abordar la ruta del Mediterráneo Central, de 3 de febrero de 2017. Igualmente, Comunicación Conjunta al Parlamento Europeo, el Consejo Europeo y el Consejo, Migración en la ruta del Mediterráneo Central. Gestionar los flujos, salvar vidas, JOIN (2017) 4 final/2 (17 de febrero de 2017); Informe de la Comisión al Parlamento Europeo, al Consejo Europeo y al Consejo, Quinto informe de situación sobre el Marco de Asociación con terceros países en el contexto de la Agenda Europea de Migración, COM (2017) 471 final (11 de septiembre de 2017), pp. 10-11. 
nominadas Petersberg, recogidas en el art. 43.1 TUE (Acosta Sánchez, 2011). Estas se traducirían en la creación de capacidades civiles y misiones de reforma del sector de la seguridad (supervisión, tutoría y asesoramiento, formación), entre otras cuestiones en relación con la Policía, el Estado de derecho, la gestión de fronteras y la lucha antiterrorista, así como la creación de capacidades militares a través de misiones de asesoramiento, formación y tutoría ${ }^{43}$.

Actualmente, en el marco de la PCSD encontramos las siguientes misiones:

a) Operación civil de Asistencia Fronteriza de la UE en Libia - EUBAM Libia $^{44}$ : sus objetivos, como claros ejemplos de externalización, son facilitar la capacitación de las autoridades libias en la gestión de las fronteras por tierra, mar y aire a corto plazo, así como elaborar una estrategia de gestión integrada de las fronteras. Además, esta operación civil ha sido capaz de ir preparando la posibilidad de crear una futura misión civil de la PCSD en Libia de naturaleza multidimensional, que incluiría los ámbitos de la policía, el Estado de derecho y la gestión de las fronteras, y proporcionando asesoramiento y formación a las autoridades libias. En cualquier caso, es fundamental la cooperación y diálogo con los países vecinos, especialmente Egipto, Túnez y Argelia.

El objetivo final sería la elaboración de un Comprehensive National Integrated Border Management (IBM) a fin de definir las competencias de las innumerables unidades responsables en la gestión de fronteras. Concretamente,

apoyará el establecimiento de un marco más amplio de gestión fronteriza, en particular a través del desarrollo de un libro blanco relativo a una estrategia de gestión integrada de las fronteras que incluya una estrategia de seguridad marítima, mediante la provisión de capacidades y la ejecución de proyectos concretos para los cuerpos de seguridad marítimos y fronterizos libios, evaluando al mismo tiempo las posibilidades de realizar sus actividades fuera de la capital, en particular en la frontera con Túnez y en el sur del país, [y] apoyará la creación de capacidades y la planificación estratégica, también por lo que respecta a los cuerpos de policía,

43 Ejemplos serían EUSEC RD CONGO y EU SSR Guinea Bissau, así como EUBAM Libia, EUBAM Moldavia y Ucrania y EUBAM Rafah. Veánse las Conclusiones del Consejo, sobre un marco estratégico a escala de la UE para apoyar la reforma del sector de la seguridad, Doc. 13998/16 (14 de noviembre de 2016).

Decisión 2013/233/PESC del Consejo, de 22 de mayo de 2013, sobre la Misión de de la Unión Europea de asistencia y gestión integrada de las fronteras en Libia (EUBAM Libia), DO L 138, de 24 de mayo de 2013. Véase la Resolución del Consejo de Seguridad 2144 (2014) de 24 de mayo. Sobre las dificultades de la misión y el error de planificación por parte de la UE al lanzarla, Christensen, Ruohomäki $y$ Rodt (2018); Díez Alcalde (2013). 
en el Ministerio del Interior en materia de cumplimiento de la ley, lo que también supone, si fuese viable, la asistencia a la Misión de Apoyo de las Naciones Unidas en Libia (UNSMIL) en sus esfuerzos de creación de capacidad policial, y apoyará las funciones de coordinación de las autoridades libias encargadas de combatir la delincuencia organizada y el terrorismo ${ }^{45}$.

En definitiva, esta operación civil afectará exclusivamente a los cuerpos de guardias de fronteras libios adscritos al Ministerio del Interior, con competencias limitadas al territorio bajo soberanía o jurisdicción del Estado y sin una clara coordinación con la Armada libia en cuanto al control de las fronteras exteriores marítimas.

Finalmente, al ser la única acción PCSD en el territorio libio, juega un rol esencial como estructura de enlace con otros sujetos sobre el terreno. En cualquier caso, es fundamental la cooperación y diálogo con los países vecinos, como ya hemos indicado anteriormente.

b) Operación militar naval EUNAVFOR MED SOPHIA ${ }^{46}$ : su misión se centra en detectar, capturar y eliminar los buques y medios que utilizan o que se sospeche que utilizan los pasadores de fronteras o los tratantes de personas, de conformidad con el derecho internacional aplicable, incluidos la Convención de Naciones Unidas sobre el Derecho del Mar así como los mandatos del Consejo de Seguridad —Resolución del Consejo de Seguridad 1970 (2011) de 26 de febrero, y posteriores-. Igualmente, y tras una modificación por Decisión 2016/993/PESC, proporciona formación a la guardia costera y a la Armada libias ${ }^{47}$, incluso en materia de derechos humanos y Derecho internacional humanitario. Cabe destacar que, debido a la negativa expresa por parte

45 Nueva redacción al art. 3.1 a) y b), de la decisión de creación, aprobada por la Decision 2018/2009/PESC del Consejo de 17 de diciembre de 2018, por el que se modifica y prorroga la Decisión 2013/233/PESC (DO L 322, de 18 de diciembre de 2018). Véase, igualmente, Strategic Review on EUNAVFOR MED Operation Sophia, cit., nota 24, pp. 48-62.

46 Decisión 2015/778/PESC del Consejo, de 18 de mayo de 2015, relativa a una operación militar de la Unión Europea en el Mediterráneo central meridional, DO L 122, de 19 de mayo de 2015. Véase la Resolución del Consejo de Seguridad 2240 (2015) de 9 de octubre. Igualmente, Carli (2018).

47 La ampliación de funciones a la formación de guardacostas se ha producido por Decisión 2016/993/PESC del Consejo, de 20 de junio de 2016 (DO L 162, de 21 de junio de 2016). La activación de esta nueva función, en Decisión 2016/1635/PESC del Comité Político y de Seguridad, de 30 de agosto de 2016 (DO L, 243, de 10 de septiembre de 2016). Véase, igualmente, la Resolución del Consejo de Seguridad 2380 (2017) de 5 de octubre. 
de las autoridades libias, las funciones de Sophia únicamente se desarrollan en alta mar. Esto último limita en la práctica las funciones de la operación, además de agravar la posible coordinación en la formación de guardacostas en las zonas bajo soberanía y jurisdicción libias, concretamente en lo que se refiere a la labor desarrollada por EUBAM Libia. Por otra parte, la operación Sophia ha sido duramente criticada por la distorsión de sus funciones, al desarrollar constantemente una labor de control y vigilancia fronteriza más allá del mandato establecido, además de problemas en cuanto a la jurisdicción sobre las personas rescatadas en el mar (Cusumano, 2019; Papastavridis, 2016).

Por otra parte, se ha creado un mecanismo de seguimiento en la formación de personal, aumentando el intercambio de información con las autoridades policiales y aduaneras de los Estados miembros, Frontex y Europol ${ }^{48}$. No obstante, los informes de evaluación distribuidos en febrero de 2018 denotan la necesidad de una mayor presencia en territorio libio, especialmente en lo que se refiere a la capacidad de información, vigilancia y reconocimiento.

Respecto a este intercambio de información, cabe destacar el lanzamiento, a través de un proyecto piloto, de una Célula de Información Criminal $(\mathrm{CIC})^{49}$, a fin de mejorar el intercambio de datos criminales, y en donde participan Frontex y Europol, así como representantes de las agencias policiales de los Estados miembros. La CIC debe facilitar el intercambio de información entre la operación Sophia y las agencias del Espacio de Libertad, Seguridad y Justicia, sin crear nuevas unidades o cambiar el marco legal. Paralelamente, Europol y Frontex cooperarán junto con la EUBAM Libia en los proyectos de formación con la Administración General de Seguridad Costera (Ministerio del Interior). A medio plazo, deberá determinarse si este proyecto piloto es extrapolable a otras misiones en el ámbito PCSD, lo cual debería conllevar una mejor coordinación de todas las acciones operativas tanto de seguridad interior como exterior sobre el terreno. Podría ser, en definitiva, un primer paso hacia una sinergia entre políticas sobre el terreno, si bien limitado a ámbitos muy concretos.

48 La autorización de crear un mecanismo de verificación fue adoptada por la Decisión del Consejo 2017/1385/PESC, de 25 de julio, DO L 194, de 26 de julio de 2017. Sobre su origen, véase, UNSMIL \& OHCHR, “Detained and Dehumanised”, Report on Human Rights Abuses against migration in Libya», de 13 de diciembre de 2016. Decisión 2018/717/PESC, del Consejo, de 14 de mayo de 2018, por la que se modifica la Decisión (PESC) 2015/778 relativa a una operación militar de la Unión Europea en el Mediterráneo central meridional (operación EUNAVFOR MED SOPHIA), DO L 120, de 16 de mayo de 2018. Véase Strategic Review on EUNAVFOR MED Operation Sophia, cit., nota 24, pp. 67-72. 
Centrándonos en la formación de los guardacostas libios ${ }^{50}$, el principal objetivo es capacitarlos para hacer frente al tráfico de personas y mejorar las labores de rescate y salvamento en la novedosa zona SAR libia. Esta actividad de formación se inició en octubre de 2016 tras la firma de un Memorandum of Understanding $(\mathrm{MoU})$ entre el comandante de la operación Sophia y el comité técnico de expertos libios y con la aprobación del Comité Político y de Seguridad (COPS) de la UE. El programa de formación estaría constituido por tres fases: formación en el mar, formación en la costa y consolidación de las aguas libias. Se incluye formación en materia SAR, primeros auxilios, procedimientos de rescate, derecho internacional de los derechos humanos, derecho internacional marítimo, lucha contra tráfico ilegal en el mar, recogida de datos de la navegación y, finalmente, procedimientos de petición de asilo e información pública. En estas sesiones han participado, entre otros, Frontex, ACNUR, Organización Internacional de las Migraciones OIM, la Oficina Europea de Apoyo al Asilo y ONG italianas en su mayoría. Desde septiembre de 2016, se ha formado a 213 miembros de la guardía costera libia y fuerzas navales. Durante 2018, se ha formado a más de 200 miembros, aumentado en 100 más en enero de 2019. La formación ha tenido lugar en Italia, España, Croacia, Grecia y Malta, y no ha estado exenta de problemas en cuanto al logro de los objetivos perseguidos, especialmente en lo que respecta la formación adecuada en materia de derechos humanos y trato no degradante. En concreto, la formación se ha realizado fundamentalmente sobre los mandos de mayor rango de los guardacostas libios, quienes no realizan las labores sobre el terreno y ni tienen contacto directo con los guardacostas que efectivamente llevan a cabo el control fronterizo y la gestión de los inmigrantes. Ello ha conllevado cuestionarse la utilidad de la formación e incluso la propia cooperación con las autoridades libias ${ }^{51}$.

Finalmente, y a efectos de coordinar la labor de todos los cuerpos afectados a la gestión y control de fronteras, se está analizando la elaboración de un marco estratégico del mecanismo de coordinación informal encabezado por el SEAE y la Comisión. En este marco, la operación Sophia está apoyando a EUBAM Libia en la elaboración de la estrategia de seguridad marítima libia y de acuerdo con las cartas cofirmadas el 9 de marzo de 2018 con el Libyan Maritime Steering Group y el National Team for Border Security and Management. Este documento es de sumo interés pues clarifica la co-partición de responsabilidades entre los componentes civiles y militares de los guardacostas

50 Véase Review on EUNAVFOR MED Operation Sophia, cit., nota 24, pp. 32-35. D’Argent y Kuritzky (2017); Mancini (2017: 266-268); Poncela Sacho (2019).

51 Entrevista del autor con miembros de la operación Sophia, el 29 de mayo de 2019. 
libios, como un primer paso de sinergia entre políticas sobre el terreno. Sin embargo, en nuestra opinión, no parece que haya tenido mucho seguimiento esta necesaria colaboración entre Sophia y EUBAM Libia, máxime cuando esta última ha sido ampliada hasta el 30 de junio de 2020 y Sophia hasta el 31 de marzo de $2020^{52}$. Y es que, además, desde marzo de 2019, Sophia no cuenta con barcos desplazados ${ }^{53}$, ante la reticencia de los Estados miembros de mantener la operación, con lo que ha conllevado su práctica finalización.

\section{ACCIONES EN EL ÁMBITO DEL ESPACIO DE LIBERTAD, SEGURIDAD Y JUSTICIA}

Por su parte, en el ámbito del Espacio de Libertad, Seguridad y Justicia, Frontex podrá desplegar operaciones a petición de un Estado miembro o bien de oficio por parte del Consejo, a propuesta de la Comisión, para el caso de grave peligro en el funcionamiento del espacio Schengen. Para el caso de desplegarse en el territorio o en aguas bajo jurisdicción de un tercer Estado, requerirá la autorización de este último. A fecha de hoy, se encuentran activas las siguientes acciones en las aguas próximas a Libia:

a) Operación naval Themis, que ha sustituido a la anterior operación Tritón, desde febrero de 2018. Su misión es el control y vigilancia de fronteras, cubriendo las aguas territoriales de Italia y las zonas SAR de Italia y Malta, representando de este modo un mecanismo de control de la inmigración irregular procedente de Libia ${ }^{54}$. Esta operación se enmarcaría en lo que se denomina Vigilancia de Fronteras Marítimas, por lo que debemos acudir para su identificación ratione materiae al Código de Fronteras Schengen ${ }^{55}$. De esta

52 Decisión 2019/1595/PESC del Consejo, de 26 de septiembre de 2019 (DO L 248, de 27 de septiembre de 2019).

53 Decisión 2019/535/PESC del Consejo, de 29 de marzo de 2019 (DO L 92, de 1 de abril de 2019). Igualmente, Strategic Review on EUNAVFOR MED Operation Sophia, cit., nota 24, p. 47. Véase Mantini (2019).

54 Véanse, en general sobre las operaciones Frontex, Carrera y Den Hertog (2015); Marin (2011). Igualmente, «Frontex Annual Report on the implementation on the EU Regulation 656/2014 of the European Parliament and of the Council of 15 May 2014 establishing rules for the surveillance of the external sea borders», Doc. 11129/18 (16 de julio de 2018).

55 Considerando (1) del Reglamento 2014/656/UE del Parlamento Europeo y del Consejo, de 15 de mayo de 2014, por el que se establecen normas para la vigilancia de las fronteras marítimas exteriores en el marco de la cooperación operativa coordinada por la Agencia Europea para la Gestión de la Cooperación Operativa en las Fronteras Exteriores de los Estados miembros de la Unión Europea, DO L 189, de 27 de junio 
forma, se incluiría: evitar el cruce no autorizado de las fronteras; la detención, el abordaje, registro, apresamiento y la interceptción del buque; y disposiciones dirigidas a situaciones de búsqueda y salvamento, lo cual incluiría el desembarco en un «lugar seguro" ${ }^{56}$.

b) La Red Seahorse. Esta red encuentra su origen en el marco atlántico, en el cual, a través del Centro de Fronteras Marítimas para el Mediterráneo Occidental, se desarrolló la operación Seahorse $e^{57}$ iniciada en 2006 cuyo objetivo era controlar las fronteras del Mediterráneo, incluidos los puertos europeos. Esta operación ha contemplado la creación de un centro regional de vigilancia marítima en Algeciras, a las que se han sumado otros dos en Las Palmas y Valencia con la finalidad de luchar contra la inmigración irregular por vía marítima. En este proyecto, liderado por la Guardia Civil española, han participado Alemania, Bélgica, Cabo Verde, España, Francia, Italia, Marruecos, Mauritania, Portugal y Senegal. Posteriormente, se ha creado una Seahorse Network para instalar una red segura de comunicación por satélite para el intercambio de información, así como los Seahorse Cooperation Centres para actividades de cooperación entre los países socios.

El éxito de la red en el marco atlántico ha hecho que se haya extendido al Mediterráneo, a través de un acuerdo de colaboración entre España, Francia, Italia, Malta, Portugal, Chipre, Grecia y Libia. El proyecto de cooperación Seahorse Mediterráneo fue aprobado por la Comisión Europea en septiem-

de 2014; y art. 13.1 del Reglamento 2016/399/UE del Parlamento Europeo y del Consejo, de 9 de marzo de 2016, por el que se establece un Código comunitario de normas para el cruce de personas por las fronteras (Código de fronteras Schengen), DO L 77, de 23 de abril de 2016. Véase Esteve García (2017).

Podemos entender como «lugar seguro» lo siguiente: «Un lugar en el que se considera que finaliza una operación de salvamento y donde la seguridad de la vida de los supervivientes no está amenazada, y pueden satisfacerse sus necesidades humanas básicas y encontrarse medios de transporte para su traslado a su destino próximo o final, teniendo en cuenta la protección de sus derechos fundamentales de conformidad con el principio de no devolución». Art. 2.12) del Reglamento 2014/656/UE, cit. supra. Véase Acosta Sánchez (2018a).

57 Véase «Enfoque Global de la migración: medidas prioritarias centradas en África y en el Mediterráneo", Anexo I de las Conclusiones de la Presidencia presentadas en el Consejo Europeo de Bruselas, diciembre de 2005, Bull. UE, núm. 12-2005, puntos I.1 y ss; Doc. de l'Assemblée de l'UEO, núm. 1920, La surveillance de l'espace maritime et des zones côtières dans les pays européens, de 6 de diciembre de 2005 . Igualmente, Europa - Sur, de 3 de marzo de 2006. 
bre de $2013^{58}$, buscando la formación de los guardacostas nacionales, dependientes del Ministerio de Defensa, en la vigilancia marítima y terrestre de Libia, incluso a través de la creación de una red de comunicaciones por satélite basado en el Sistema Europeo de Vigilancia de Fronteras (Eurosur). La formación, en paralelo a la desarrollada por Sophia, incluiría: formación marítima (operaciones marítimas y de rescate), vigilancia de fronteras, reparación y mantenimiento de patrullas, código de conducta policiales y respeto de los derechos humanos de los migrantes, entre otras cuestiones. Frontex, además, debe apoyar esta cooperación mediante una supervisión constante ${ }^{59}$. Aunque la idea era activar la red en 2017, no ha sido posible hacerlo hasta finales de 2018 debido a la situación volátil de la seguridad.

Es interesante destacar que la red Seahorse Mediterráneo, si bien podemos encuadrarla como una acción en el contexto del Espacio de Libertad, Seguridad y Justicia, tiende a la formación de los guardacostas pertenecientes a la Armada libia. Ello puede entenderse por el particular régimen de sus componentes, donde si bien poseen una naturaleza civil, su estatuto es militar, tal y como ocurre con la Guardia Civil. Se persigue, entonces, lograr una sinergia entre esta red y la operación Sophia, e incluso cubrir todo el marco operativo en la formación una vez finalice la operación naval militar de la UE.

\section{EL APOYO A ITALIA}

Sin duda alguna, la mayor contribución en la formación y apoyo a las autoridades libias en materia de inmigración procede de Italia, y con el apoyo de la UE. En efecto, Italia, siendo el principal Estado miembro afectado por la crisis migratoria en el Mediterráneo central, lanzó la operación Mare Nostrum en 2013 con la función esencial de rescate y salvamento (Vacas Fernández, 2016: 97-98). En 2014, la misión fue sustituida por la operación Frontex Tri-

58 Véase Europa Press, «España y otros siete países del Mediterráneo firman un marco de colaboración para luchar contra la inmigración ilegal», de 19 de septiembre de 2013; Nota de Prensa de la Guardia Civil, «El Comité de Dirección del Proyecto Seahorse se reúne en la Dirección General de la Guardia Civil», de 1 de abril de 2014. Igualmente, Comunicación Conjunta al Parlamento Europeo, el Consejo Europeo y el Consejo, Migración en la ruta del Mediterráneo Central. Gestionar los flujos, salvar vidas, JOIN(2017) 4 final/2 (17 de febrero de 2017); Joint Staff Working Document, Second report on the implementation of the EU Maritime Security Strategy Action Plan, Doc. 10398/1/17 REV 1 (19 de junio de 2017); Conclusiones del Consejo sobre seguridad marítima mundial, Doc. 10238/17 (19 de junio de 2017); Strategic Review on EUNAVFOR MED Operation Sophia, cit., nota 24, p. 78.

59 Véase, art. 4 e) del Reglamento Frontex. 
tón, pero con una importante modificación en su finalidad al tratarse de una acción claramente de control fronterizo, lo cual conllevó numerosas críticas debido a su naturaleza deshumanizadora (Tazzioli, 2016).

Igualmente es interesante destacar el Memorandum of Understanding - MoU entre Italia y Libia de febrero de 2017. Este acuerdo, de dudosa naturaleza jurídica como tratado internacional (Zambrano, 2019: 129-130), implanta un proyecto plurianual para reforzar la vigilancia de las fronteras libias, prestar asistencia en el marco de operaciones SAR y la creación de un Centro de Coordinación de Salvamento Marítimo. Igualmente, incluye la formación de los guardacostas, especialmente aquellos destinados en los centros de acogida de inmigrantes en territorio libio (Mancini, 2017: 260262; Palladino, 2018: 116-119). Este acuerdo contó inmediatamente con apoyo de la UE en la Cumbre de La Valeta, lanzándose un plan de acción sobre medidas para apoyar a Italia, que ha previsto la financiación a través del Fondo Fiduciario de la UE para África (Trust Fund for Africa), con un importe total de 46,3 millones de euros, de los cuales 42,2 millones proceden de dicho fondo, 2,2 millones de las arcas italianas, y 1,8 millones del Fondo de Seguridad Interior ${ }^{60}$.

No obstante, esta acción de las autoridades italianas, con apoyo europeo, no ha estado exenta de críticas, especialmente por lo que respecta a la formación de los cuerpos y fuerzas de seguridad destinados en los centros de acogida de inmigrantes donde, de acuerdo con informes independientes e incluso de Naciones Unidas, se han producido claras violaciones de los derechos humanos. Y es que de ello podría incluso derivarse responsabilidad internacional tanto por parte de Italia como de la UE al apoyar económicamente y con recursos materiales a individuos e infraestructuras libias responsables de tales

60 Véase Action Plan on measures to support Italy, reduce pressure along the Central Mediterranean route and increase solidarity, SEC (2017) 339 (4 de julio de 2017). Igualmente, Informe de la Comisión al Parlamento Europeo, al Consejo Europeo y al Consejo, Quinto informe de situación sobre el Marco de Asociación con terceros países en el contexto de la Agenda Europea de Migración, COM (2017) 471 final (11 de septiembre de 2017). También, Respuesta de la Vicepresidenta Mogherini en nombre de la Comisión a Pregunta con solicitud de respuesta escrita E-006077/2017, Ataques en aguas internacionales de la guardia costera libia a ONG europeas que realizan labores de rescate de refugiados en el Mar Mediterráneo, de 29 de marzo de 2018; Respuesta del Sr. Hahn en nombre de la Comisión Europea a pregunta con solicitud de respuesta escrita E-004605/2018, Financiación de la guardia costera libia por parte de la UE, de 12 de diciembre de 2018. 
violaciones (Amnesty International, 2017; Loschi et al., 2018: 6-9; Mancini, 2017: 273-274; Naciones Unidas, 2017; Palladino, 2018: 124-128) ${ }^{61}$.

\section{LA NECESARIA SINERGIA DE POLÍTICAS EUROPEAS: UNA PROPUESTA}

Vemos entonces cómo se están desarrollando distintas actuaciones operativas, tanto en el ámbito de la seguridad y defensa a través de la PCSD, como en la dimensión exterior del Espacio de Libertad, Seguridad y Justicia, y todas ellas en el marco de la externalización del control fronterizo, persiguiendo objetivos similares cuales son la formación de los guardacostas libios. No obstante, no se percibe una coordinación entre todas estas actuaciones, al no existir un órgano o unidad a nivel de la UE que regule la formación, con independencia de la naturaleza civil o militar de los agentes. La situación de inseguridad en el país y las dificultades de las acciones operativas sobre el terreno han agravado además esta posible coordinación.

Ello hace imprescindible una sinergia y coordinación entre políticas frente a las amenazas a la seguridad, como es la lucha contra la criminalidad organizada responsable del tráfico de personas, tal y como se viene reconociendo desde la Estrategia Europea de Seguridad de $2003^{62}$. Del mismo modo, para la Agenda Europea de Seguridad, de abril de $2015^{63}$, las amenazas a la seguridad no se ven confinadas a las fronteras de la UE. Además, la seguridad

61 Véase Pregunta con solicitud de respuesta escrita E-000945/2017, Entrenamiento, equipamiento y apoyo de la guardia costera libia, de 9 de febrero de 2017; Pregunta con solicitud de respuesta escrita E-006077/2017, Ataques en aguas internacionales de la guardia costera libia a ONG europeas que realizan labores de rescate de refugiados en el mar Mediterráneo, de 29 de septiembre de 2017; Pregunta con solicitud de respuesta escrita E-007276/2017, Incidente con la guardia costera libia, de 27 de noviembre de 2017; Pregunta con solicitud de respuesta escrita E-004603/2018, Financiación por la UE de la Guardia Costera libia, de 11 de septiembre de 2018; Pregunta con solicitud de respuesta escrita E-004604/2018, Financiación de la UE de la Guardia Costera libia, de 11.09.2018; Pregunta con solicitud de respuesta escrita E-004605/2018, Financiación de la Guardia Costera libia por parte de la UE, de 11 de septiembre de 2018.

62 Estrategia Europea de Seguridad, «Una Europa Segura en un Mundo Mejor», Bruselas, de 12 de diciembre de 2003.

63 Comunicación de la Comisión al Parlamento Europeo, al Consejo, al Comité Económico y Social Europeo y al Comité de las Regiones, Agenda Europea de Seguridad, COM (2015) 185 final (28 de abril de 2015). 
interior y exterior son interdependientes y están relacionadas, por lo que la respuesta de la UE debe ser global y basarse en un conjunto coherente de acciones que combinen ambas dimensiones, a fin de reforzar los vínculos entre justicia e interior y la PCSD. Para ello es esencial la cooperación con otros socios internacionales, especialmente los países vecinos ${ }^{64}$. Con todo, lo que se defiende respecto a la formación de guardacostas, sean de naturaleza civil o militar (política interior/política exterior), es una formación similar a partir de unos parámetros básicos y comunes y particularmente compatibles con estándares internacionales y europeos.

A la hora de determinar la necesaria sinergia entre las diversas manifestaciones en el ámbito de la formación de guardacostas libios, dependan de los ministerios del Interior o de Defensa, conviene tener presente la propia situación en los países de la UE. Y es que, como indica la propia Comisión, «existen actualmente más de 300 autoridades civiles y militares responsables de guardacostas en un amplio conjunto de ámbitos, como la seguridad, la protección marítima, búsqueda y salvamento, el control de fronteras, el control pesquero, el control aduanero, las labores policiales y la protección del medio ambiente» ${ }^{65}$. Ello nos lleva ya a asumir una primera idea: la diversificación de unidades con competencias fronterizas no es algo ajeno a Europa y ello evidentemente redunda en las dificultades que podamos encontrar a la hora de buscar elementos de cohesión en la propia formación de dichas unidades. En nuestra opinión, el esquema seguido por la Administración libia en materia de control y gestión de fronteras obedece a una estructura tradicional, segui$\mathrm{da}$ en nuestro entorno, pero que incluye un elemento adicional que provoca en nuestra opinión una posible distorsión. Y es la participación de la fuerza armada naval en el ámbito propio de seguridad interna, es decir, el control de fronteras.

Ya se ha analizado esta cuestión tomando como modelo el complejo alcance funcional de la operación Sophia (Acosta Sánchez, 2018b; Bevilaqua, 2017; Fernández-Rojo, 2019). No obstante, conviene recordar la ampliación del concepto de seguridad tras el fin de la Guerra Fría, procediéndose a una reducción de la posibilidad de un ataque armado contra el territorio de un

64 La Estrategia de Seguridad Marítima de la UE habla de «enfoque intersectorial». Véase Estrategia de Seguridad Marítima de la Unión Europea, Doc. 11205/14 (24 de junio de 2014). Igualmente, Estrategia de Seguridad Marítima de la Unión Europea (ESMUE): Plan de acción, Doc. 17002/14 (16 de diciembre de 2014). Aquí entrarían concretamente Túnez, Argelia y Egipto.

65 Comunicación de la Comisión al Parlamento Europeo y al Consejo, La Guardia Europea de Fronteras y Costas y la gestión eficaz de las fronteras exteriores de Europa, COM (2015) 673 final (15 de diciembre de 2015), p. 7. 
Estado, esto es, un acto de agresión propia de la dimensión exterior de la seguridad (Álvarez Verdugo, 2004: 29-59; Echeverría Jesús, 2013). Todo ello se puede apreciar, además, con el surgimiento de nuevos riesgos y amenazas de diferente naturaleza, como es el terrorismo, identificando una serie de riesgos nacionales que poseían una dimensión transnacional. De esta forma, la seguridad interior, parte del núcleo duro de la soberanía estatal, comienza a disponer de un carácter internacional. Con todo, la actual composición doble de la seguridad, interior y exterior, representa, en nuestra opinión, un acercamiento de los instrumentos existentes en poder del Estado, de tal forma que los medios militares, propios de la dimensión exterior, podrán ser aplicados en el ámbito interno de la seguridad; y, por su parte, la seguridad interior dispondrá de una proyección exterior a través de medios civiles, policiales y judiciales y en el contexto del multilateralismo ${ }^{66}$. Con todo, nos encontramos dos dimensiones de la seguridad íntimamente relacionadas, de tal forma que se busquen, por parte tanto de los entes estatales como de las organizaciones internacionales, mecanismos coherentes y eficaces para dar una respuesta eficaz ante los riesgos y las amenazas; en definitiva: un enfoque integral frente a las crisis.

En este orden de cosas y centrándonos en la formación de guardacostas, la UE ha tenido ya una experiencia considerable. De este modo, las actuales operaciones militares en el ámbito de la PCSD, partiendo del enfoque integrado, llevan entre sus funciones la formación de las fuerzas armadas dentro de unos estándares mínimos ${ }^{67}$. A ello se añaden las propias operaciones policiales de la $\mathrm{UE}^{68} \mathrm{e}$ incluso las destinadas a la gestión fronteriza ${ }^{69}$. No obstante, el mandato de cada una de ellas, unido a la realidad del terreno en el cual se han aplicado, determinan que cada operación debe adaptarse al mandato y a las circunstancias de cada operación. Por ello no es posible, inicialmente, establecer marcos comunes en materia de formación.

Por otra parte, el propio TUE, en sus arts. 21.3 y 26.2, indica la necesaria coherencia, unidad y eficacia de la acción de la Unión en la aplicación de todas sus políticas ${ }^{70}$. Para ello, deberán actuar conjuntamente el Consejo, la Co-

66 Ejemplo de ello serían las operaciones de carácter policial en el ámbito tanto de $\mathrm{Na}$ ciones Unidas como de la UE.

67 Ejemplo son las operaciones EUTM en Somalia, Mali y Chad.

68 EUPM en Bosnia-Herzegobina, EUPOL COPPS en los Territorios Palestinos, o EUPOL RD Congo.

69 EUBAM Moldova y Ucrania, EUBAM Libia o EUBAM Rafah. Un análisis de todas estas operaciones, en Barceló (2015).

70 Para el Parlamento Europeo, «los límites entre seguridad exterior y seguridad interior están cada vez más difuminados; solicita, por consiguiente, una mayor coherencia 
misión y el Alta Representante. La creación del Servicio Europeo de Acción Exterior en el seno del Consejo, así como el «doble sombrero» que ostenta el Alta Representante, han facilitado esta necesaria coherencia. Además, la actual Estrategia Global de Seguridad, de junio de 2016, en su sección 4. ${ }^{a}$ incide en esta idea, promoviendo el intercambio de información para un mejor conocimiento del terreno ${ }^{71}$ e incluyendo la protección de derechos humanos y las cuestiones de género. En materia migratoria incluso afirma la necesaria coherencia entre las acciones PCSD con las políticas internas como es la gestión de fronteras ${ }^{72}$.

Sin embargo, nos encontramos con dos elementos esenciales a tener en cuenta. El primero de ellos es que nos hallamos, en materia de formación de fuerzas extranjeras — sean policiales o militares —, en un ámbito intergubernamental, con claro control por parte del Consejo y en donde los Estados miembros poseen un amplio margen discrecional de decisión. El segundo es que a fecha de hoy no consta la existencia de una unidad especializada en el ámbito de la PCSD o incluso del Servicio Europeo de Acción Exterior con competencias sobre la coordinación en materia de formación en las acciones operativas exteriores.

En nuestra opinión, la vinculación entre políticas interiores y exteriores de la UE para una misma finalidad, como sería en este caso el control fronterizo, la reforma del sector de la seguridad, la formación de guardacostas y la lucha contra la criminalidad organizada transnacional, debería pasar irre-

entre los instrumentos externos e internos, así como una cooperación y coordinación reforzada entre los Estados miembros, especialmente en los ámbitos de la lucha contra el terrorismo, la delincuencia organizada, la ciberdefensa y la migración, bajo el liderazgo de la VP/AR». Véase la Resolución del Parlamento Europeo, de 21 de mayo de 2015, aplicación de la política común de seguridad y defensa, DO C 353, de 27 de septiembre de 2016, apdo. 3.

71 Un ejemplo sería la promoción del intercambio de información entre las operaciones en el ámbito PCSD con aquellas del Espacio de Libertad, Seguridad y Justicia en Libia. Véase Strategic Review on EUNAVFOR MED Operation Sophia, cit., nota 24. Estrategia Global sobre Política Exterior y de Seguridad de la Unión Europea, Doc. 10715/16 (28 de junio de 2016), sección 4. a , «De la visión a la acción». Igualmente, Comunicación conjunta al Parlamento Europeo y al Consejo, el enfoque integral adoptado por la UE en relación con los conflictos y las crisis exteriores, COM (2013) 30 final (11 de diciembre de 2013); Comunicación de la Comisión al Parlamento Europeo, al Consejo Europeo y al Consejo, contribución de la Comisión al debate temático de los dirigentes de la UE sobre los futuros pasos en relación con las dimensiones interna y externa de la política de migración, COM (2017) 820 final/2 (13 de diciembre de 2017). 
mediablemente por una coordinación entre agencias o acciones de diversa índole, interior y exterior. Es necesario superar, de este modo, la línea divisoria excesivamente estricta entre funciones del ámbito de la PCSD y del ámbito del Espacio de Libertad, Seguridad y Justicia, que dificulta el enfoque integral de la respuesta europea. Las propuestas presentadas por la Comisión ya en $2013^{73}$ parecen ir en la buena dirección, si bien convendría profundizarlas adecuadamente:

- La necesidad de colaboración estrecha entre el Alta Representante y el presidente de la Comisión Europea para garantizar la coherencia estratégica y operativa de relaciones exteriores, en particular por lo que se refiere a los efectos externos de las políticas internas. Se vería entonces procedente una mayor implicación de la Comisión en el SEAE, con inclusión de miembros en sus unidades y en coordinación con sus homólogos del Consejo. Sobre el terreno, las delegaciones de la UE deberían jugar un papel esencial en este ámbito.

- Utilizar mejor los medios diplomáticos y las relaciones exteriores a disposición de la UE y defender sus intereses en relación con las políticas internas y los problemas internacionales, buscando protocolos de coordinación entre políticas. En definitiva, una acción integrada en el ámbito exterior europeo.

- Intentar determinar y dar a conocer las políticas y los instrumentos que tienen una dimensión interna y externa y destacar el potencial en ambas direcciones. La promoción de lo que podríamos denominar «cultura de la seguridad» entre la ciudadanía conllevaría un mayor acercamiento a la realidad operativa de la UE, mejorando la valoración que pudieran tener los ciudadanos respecto a su dimensión internacional.

- Que las políticas internas formen parte del marco de análisis de las crisis, la reflexión estratégica y los documentos relativos a la política de acción exterior siempre que sea posible y pertinente. De esta forma, no necesitaríamos dos regímenes o estrategias de seguridad - interior y exteriorsino únicamente una que fuera global e integrada.

No obstante, se podría ser aún más ambicioso en el planteamiento. En los últimos tiempos hemos sido testigos de la creación de unidades o células a fin de facilitar la gestión de las acciones operativas. Así, en sede del SEAE

73 Véase Comunicación conjunta al Parlamento Europeo y al Consejo, El enfoque integral adoptado por la UE en relación con los conflictos y las crisis exteriores, COM (2013) 30 final (11 de diciembre de 2013). 
se dispone de una Dirección General de Crisis y Planificación (DGCP), con responsabilidad en la planificación política y estratégica de las operaciones PCSD (Simon, 2010: 25). Y en el caso concreto de Libia, se han ideado la Célula de Planificación y Enlace (EULPC) y la Célula de Información Criminal (CIC), las cuales facilitan, además, el enlace y conexión entre todas las acciones operativas y agentes de la UE sobre el terreno, aglutinando y dando cierta coherencia al conjunto de políticas aplicables. Con esta perspectiva, podríamos vislumbrar mejoras en la coordinación de medidas interiores y exteriores en el contexto de la seguridad.

Así, tomando como modelo la EULPC, tendríamos la opción de crear una unidad similar, pero con un carácter global y ubicado en la sede del SEAE. Esto es, el establecimiento de una unidad especializada y destinada a la coordinación de todas las operaciones de la UE, en los ámbitos de seguridad interior y exterior y que actuaría, bajo la dirección del Consejo y del Alta Representante, a fin de ofrecer un enfoque integrado en la respuesta europea.

Actualmente la EULPC está formada únicamente por expertos militares. En el caso del mandato de reforma del sector de la seguridad, y más concretamente en el de la formación de guardacostas de un tercer Estado, se plantearía la constitución de una unidad con un amplio equipo humano de expertos en cada una de las secciones afectadas. Esto es, una célula amplia con subsecciones por categorías. Así, esta célula a la cual podríamos denominar Célula de Planificación en el Sector de la Seguridad (European Union Security Sector Planning Cell - EUSSP), partiría de un concepto actual de la seguridad, incorporando personal tanto militar como civil, como policías, otro personal civil o funcionarial, etc. Las diversas subsecciones irían a cubrir todo el espectro del ámbito de la reforma del sector de la seguridad, desde la formación en materia de justicia pasando por la formación de las fuerzas armadas o de los cuerpos y fuerzas de seguridad con especial incidencia en la gestión y control fronterizo.

No se partiría de cero, necesariamente. La actual Dirección General de Crisis y Planificación (DGCP), ubicada en el SEAE, cuenta ya con una dirección sobre gestión civil de crisis (DG E 9), con funciones sobre los aspectos civiles de la PCSD, tales como el Estado de derecho, la administración civil, la protección civil y la formación, incluyendo además una Unidad de Policía. Por su parte, Frontex cuenta con una División de Desarrollo de Capacidades (Capacity Building Division) con competencias en materia de formación. La propuesta aquí presentada pasaría, entonces, por desgajar estas unidades de la DGCP y de Frontex a fin de constituir los elementos integradores de la futura Célula de Planificación en el Sector de la Seguridad, facilitando su puesta en marcha. A estos efectos, además de una mejor preparación y cohesión, se observaría esencial la participación de la Agencia Europea para la Formación 
Policial y la Escuela Europea de Seguridad y Defensa ${ }^{74}$, a fin de dar un contenido coherente a toda la formación impartida y en íntima relación con las instituciones nacionales competentes.

\section{IDEAS FINALES}

En nuestra opinión, la respuesta al fenómeno migratorio debe ser una respuesta global, multidimensional y que agrupe actuaciones en varios ámbitos. Así, la promoción de una sinergia entre políticas interiores y exteriores, entre seguridad interior y exterior, se observa esencial. Y ello implicaría igualmente la cooperación transfronteriza con los países relevantes de la región sur del Mediterráneo, especialmente Túnez, Egipto, Libia y Argelia, así como una mejora de la cooperación al desarrollo y medidas diplomáticas eficaces y respetuosas con la identidad nacional de los países afectados.

En el ámbito de la formación de guardacostas, y en el contexto de la gestión integrada de fronteras, observamos un claro elemento donde poner en práctica esta sinergia. De esta forma, la compleja realidad libia, donde nos encontramos gran variedad de unidades con competencias en el control y vigilancia fronterizo, ha llevado a que la UE lance una serie de acciones operativas en el marco de diversas políticas. Parece entonces necesario disponer de operaciones en el marco de la PCSD con un mandato claro y coherente y actuando en el marco de una estrategia global previamente establecida por la UE, pero igualmente una actuación más coherente por parte de Frontex. Y en esa función de sinergia, de coordinación y de coherencia en el ámbito del Mediterráneo central, la función esencial debe recaer en el Alta Representante y la estructura de apoyo ubicada en el SEAE y de la célula propuesta en el presente estudio. Así, la creación de una unidad permanente y funcional, además de extrapolable a cualquier situación, permitiría a la Unión fortalecer más si cabe su presencia en el contexto internacional, a través de una acción integrada, global y más acorde con las necesidades actuales. Todo ello con pleno respeto de los derechos humanos, tanto en la formación de los guardacostas como en

74 Reglamento 2015/2219/UE del Parlamento Europeo y del Consejo, de 25 de noviembre de 2015, sobre la Agencia de la Unión Europea para la formación policial (CEPOL) y por el que se sustituye y deroga la Decisión 2005/681/JAI del Consejo, DO L 319, de 4 de diciembre de 2015; Decisión 2016/2382/PESC del Consejo, de 21 de diciembre de 2016, por la que se crea la Escuela Europea de Seguridad y Defensa (EESD) y por la que se deroga la Decisión 2013/189/PESC, DO L 352, de 23 de diciembre de 2016. 
una función in vigilando a posteriori de las tareas desarrolladas por aquellos que han recibido la formación.

No obstante, el principal obstáculo que puede encontrar esta actuación conjunta es el peso dispar que tienen los Estados miembros en el contexto de la política migratoria, así como la inaceptable falta de solidaridad ante este fenómeno y su compromiso para alcanzar objetivos concretos y realistas. Es preciso asumir que la inmigración irregular, más concretamente la criminalidad organizada que trafica con seres humanos, es un reto común a todos, y únicamente una acción conjunta, eficaz y políticamente integrada, podrá hacer frente a esta amenaza común.

En conclusión, la respuesta global a las nuevas amenazas a la seguridad no puede llevarse a cabo de forma unilateral por medio de una única política. Debe conllevar, en cambio, un recurso a todo el elenco de medidas de que dispone la UE a fin de hacer frente a las mismas. Con ello se pretende poner en boga la necesidad de una interconexión entre políticas, de una sinergia que afecte a las políticas exteriores con aquellas interiores a fin de hacer frente a los riesgos que la UE debe afrontar en el siglo Xxi. La comunidad internacional lo necesita, y una UE solidaria y comprometida aún más, si realmente desea afianzar y hacer creíbles los valores y principios que dieron origen a su proceso de integración.

\section{Bibliografía}

Acosta Sánchez, M. A. (2011). The EU's Military Crisis Management Operations. Petersberg Tasks and International Peace. Saarbrücken: Lambert Academic Publishing.

Acosta Sánchez, M. A. (2018a). The Notions of Safe Country v. Prima Facie Presumption of Entitlement to International Protection. The Spanish practice. Diritti Umani e Diritto Internazionale, 2, 511-522.

Acosta Sánchez, M. A. (2018b). Sobre el ámbito competencial de las operaciones de paz: el enfoque integral de la operación militar Sophia de la UE ante la crisis migratoria. Revista del Instituto Español de Estudios Estratégicos, 12, 15-48.

Álvarez Verdugo, M. (2004). La politica de seguridad y defensa de la UE. Madrid: Editorial Dykinson.

Amnesty International (2017). Libya's Dark Web of Collusion. Abuses against Europe-Bound Refugees and Migrants, 11-12-2017.

Asociación Pro Derechos Humanos de Andalucía (2019). Derechos Humanos en la Frontera Sur 2019, 7-2-2019.

Barceló, M. J. (2015). Las misiones de paz de la Unión Europea. Valencia: Editorial Tirant lo Blanch. 
Bevilacqua, G. (2017). Exploring the Ambiguity of Operation Sophia between Military and Search and Rescue Activities. En G. Andreone (ed.). The future of the Law of the Sea (pp. 165-189). Cham: Springer. Disponible en: https://doi. org/10.1007/978-3-319-51274-7_9.

Blanc Altemir, A. (2012). La Unión Europea y el Mediterráneo. De los primeros Acuerdos a la Primavera Árabe. Madrid: Editorial Tecnos.

Calvo Mariscal, L. (2018). La inmigración y el asilo en las fronteras de Europa: el caso de Libia. Ateneo: Revista Cultural del Ateneo de Cádiz, 18, 149-156.

Carli, E. (2018). Operation EUNAVFOR MED Sophia in the framework of the European Agenda on Migration: Practical aspects and questions of International Law. Freedom, Security and Justice, European Legal Studies, 2, 135-151. Disponible en: http://dx.doi.org/10.26321/E.CARLI.02.2018.06.

Carrera, S. y Den Hertog, L. (2015). Whose mare? Rule of Law challenges in the field of European border surveillance in the Mediterranean. Paper in Liberty and Security in Europe, 79. Centre for European Policy Studies.

Cervell Hortal, M. J. (2013). La interacción Naciones Unidas-Unión Europea frente a las crisis humanitarias (reflexiones a la luz del asunto libio). En A. Blanc Altemir (dir.). Las relaciones entre las Naciones Unidas y la Unión Europea: seguridad, cooperación y derechos humanos (pp. 371-396). Madrid: Editorial Tecnos.

Christensen, G. H., Ruohomäki, J. y Rodt, A. P. (2018). The European Union Border Assistance Mission in Libya - successes, shortcomings and lessons identified. Royal Danish Defence College Brief.

Comité Español de Ayuda al Refugiado (2018). Informe 2018: las personas refugiadas en España y Europa.

Cusumano, E. (2019). Migrant rescue as organized hypocrisy: EU maritime missions offshore Libya between humanitarism and border control. Cooperation and Conflict, 54 (1), 3-24. Disponible en: https://doi.org/10.1177/0010836718780175.

D’Argent, P y Kuritzky, M. E. (2017). Refoulement by Proxy? The Mediterranean Migrant Crisis and the Training of Libyan Coast Guards by EUNAVFOR MED Operation Sophia. Israel Yearbook on Human Rights, 47, 233-264. Disponible en: https://doi.org/10.1163/9789004341951_010.

De Bruycker, P. (2016). The European Border and Coast Guard: A new Model Built in an old logic. European Papers, 1, 559-569.

Del Valle Gálvez, A. (2016a). Los refugiados, las fronteras exteriores y la evolución del concepto de frontera internacional. Revista de Derecho Comunitario Europeo, 55, 759-777.

Del Valle Gálvez, A. (2016b). Unión Europea, crisis de refugiados y «limes imperii». Revista General de Derecho Europeo, 38.

Del Valle Gálvez, A. (2019). Refugiados y crisis migratorias: fronteras y desterritorialización en las puertas de Europa. En S. Ripol Carulla (dir.). Derecho, Inmigración y Empresa (pp. 85-112). Barcelona: Editorial Marcial Pons.

Díez Alcalde, J. (2013). EUBAM Libya: Seguridad fronteriza para la estabilización nacional y regional. IEEE Documento Análisis, 36. Instituto Español de Estudios Estratégicos. 
Echeverría Jesús, C. (2013). Relaciones Internacionales III. Paz, seguridad y defensa en la Sociedad Internacional. Madrid: Universidad Nacional de Educación a Distancia.

Echeverría Jesús, C. (2018). La vigencia del terrorismo yihadista en el triángulo Argelia-Túnez-Libia. Revista Ejército, 930, 114-115.

Ekiz, S. (2018). EU Strategyin Libya: Discourses vs Actions. European Foreign Affairs Review, 23, 405-425.

El Zaidy, Z. (2019). EU Migration policy towards Libya. Friedrich Ebert Stiftung.

Esteve García, F. (2017). The Search and Rescue Tasks Coordinated by the European Border and Coast Guard Agency (Frontex) Regarding the Surveillance of External Maritime Borders. Revista Paix et Sécurité Internationales, 5, 93-116. Disponible en: https://doi.org/10.25267/Paix_secur_int.2017.i5.04.

Esteve Moltó, J. E. (2014). La Unión Europea y el conflicto libio: de la intervención armada a la desprotección de los refugiados. En I. Reig Fabado. Libertad de circulación, asilo y refugio en la Unión Europea (pp. 17-40). Valencia: Editorial Tirant lo Blanch.

Fernández-Rojo, D. (2019). La Estrategia Global de Seguridad y el creciente vínculo entre la dimensión interna y externa de la seguridad de la UE: la operación naval EURONAVFOR SOPHIA. En D. Fernández-Rojo, I. Herbosa Martínez, N. Magallón Elósegui (auts.) y B. Pérez de las Heras (coord.) (pp. 14-25). Nuevos desarrollos en la seguridad y defensa europea: ¿hacia una politica más integrada de la Unión post-Brexit? Madrid: Fundación Alternativas.

Ferrer Lloret, J. (2012). La Unión Europea ante la crisis libia ¿derecho internacional, democracia y derechos humanos en las relaciones euromediterráneas? Revista de Derecho Comunitario Europeo, 41, 13-56.

Hermoso, E. (2016). Lecciones aprendidas por la Unión Europea aplicables en Libia. Revista de Estudios en Seguridad Internacional, 2 (2), 171-204. Disponible en: https://doi.org/10.18847/1.4.8.

Hernández Ospina, A. J. y García Perilla, J. C. (2018). Incidencia del problema de seguridad libio en la actual crisis migratoria. Saber Ciencia y Libertad, 13 (2), 36-49. Disponible en: https://doi.org/10.18041/2382-3240/saber.2018v13n2.4608.

International Crisis Group (2016). The Libyan Political Agreement: Time for a Reset. Middle East and North Africa Report, 170.

International Crisis Group (2017). How Libya's Fezzan Became Europe's New Border. Middle East and North Africa Report, 179.

Kekilli, E. (2019). The Libya Crisis and the Future of Khalifa Haftar. The New Turkey.

Lacher, W. (2013). Fault lines of the revolution: political actors, camps and conflicts in the new Libya. SWP Research Paper, 4. Disponible en: https://bit.ly/2N46IDK.

Loschi, C., Raineri, L y Strazzari, F. (2018). The implementation of the EU Crisis Response in Libya: Bridging theory and practice. EUNPACK, Working Paper, 6-9.

Mancini, M. (2017). Italy's new migration control policy: Stemming the flow of migrants from Libya without regard their human rights. Italian Yearbook of Inter- 
national Law, 27, 259-281. Disponible en: https://doi.org/10.1163/2211613302701015.

Mangas Martín, A. (2011). La autorización del uso de la fuerza armada en Libia. ARI: Análisis Real Instituto Elcano, 57. Real Instituto Elcano.

Mantini, G. (2019). A EU Naval Mission without Navy. The paradox of Operation Sophia. Istituto Affari Internazionali, 19-33.

Marin, L. (2011). Policing the EU's external borders: A challenge for the rule of law and fundamental rights in the area of freedom, securitity and justice? An analysis of Frontex joint operations ant the Southern Maritime border. Journal of Contemporary European Research, 7 (4), 468-487.

Mora Tebas, J. A. (2017). G5 Sahel: la Fuerza (antiterrorista) Conjunta (FC-G5S). IEEE Documento Análisis, 37, 102-119. Instituto Español de Estudios Estratégicos.

Naciones Unidas. Alto Comisionado para los Derechos Humanos (2017). Suffering of Migrants in Libya Outrage to Conscience of Humanity, 14-11-2017.

Palladino, R. (2018). Nuovo quadro di partenariato dell'Unione europea per la migrazione e profili di responsabilità dell'Italia (e dell'Unione europea) in riferimento al caso líbico. Freedom, Security and Justice. European Legal Studies, 2, 104-134. Disponible en: http://dx.doi.org/10.26321/R.PALLADINO.02.2018.05.

Papastavridis, E. (2016). EUNANFOR MED Operation Sophia and the question of jurisdiction over transnational organized crime at sea. Questions of International Law, 19-34.

Pérez Quiles, J. J. (2018). La Agencia Europea de Fronteras y Guardacostas, Frontex. Revista Jurídica de la Región de Murcia, 52, 143-156.

Poncela Sacho, A. (2019). La formación de la Guardia Costera y Marina libias en el marco de la operación Sophia. Un ejemplo práctico de la externalización de las fronteras en el ámbito de la UE. Documento de Opinión, 65. Instituto Español de Estudios Estratégicos.

Rijpma, J. J. (2009). EU Border Management After the Lisbon Treaty. Croatian Yearbook of European Law and Policy, 5, 121-149. Disponible en: https://doi. org/10.3935/cyelp.05.2009.78.

Rodríguez, B. (2016). El conflicto político libio y el conflicto armado interno. Análisis Grupo de Estudios sobre Seguridad Internacional, 27.

Sánchez Legido, A. (2019). Externalización de controles migratorios vs Derechos Humanos. Revista Electrónica de Estudios Internacionales, 37. Disponible en: https://doi.org/10.17103/reei.37.03.

Santos Vara, J. (2018). La transformación de Frontex en la Agencia Europea de la Guardia de Fronteras y Costas: ¿Hacia una centralización en la gestión de las fronteras? Revista de Derecho Comunitario Europeo, 59, 143-186. Disponible en: https://doi.org/10.18042/cepc/rdce.59.04.

Simon, L. (2010). Command and control? Planning for EU military operations. European Union Institute for Security Studies Paper, 81. 
Tazzioli, M. (2016). Border displacements. Challenging the politics of rescue between Mare Nostrum and Triton. Migration Studies, 1-19. Disponible en: https://doi. org/10.1093/migration/mnv042.

Vacas Fernández, F. (2016). The European operations in the Mediterranean Sea to deal with migration as a symptom. From the Italian Operation Mare Nostrum to Frontex operations Triton and Posseidon, EUNAVFOR-MED and NATO's assistance in the Aegean Sea. Spanish Yearbook of Internacional Law, 20, 93-117. Disponible en: https://doi.org/10.17103/sybil.20.07.

Wehrey, F. y Harchaoui, J. (2018). Is Libya Finally Ready for Peace? The Palermo Summit and the Case for Optimist. Foreign Affairs. 30-11-2018. Disponible en: https://fam.ag/2W84HdI.

Zambrano, V. (2019). Accordi informali con stati terzi in materia di gestione dei flussi migratori: considerazioni critiche con riferimento alla prassi dell'Unione europea e dell'Italia. Freedom, Security and Justice. European Legal Studies, 1, 119-148. Disponible en: http://dx.doi.org/10.26321/V.ZAMBRANO.01.2019.06. 